\title{
Eric Hobsbawm, sociólogo del milenarismo campesino
}

\begin{abstract}
RESUMEN
Gracias a la problemática del milenarismo, la historiografía de Eric Hobsbawm integra toda la riqueza de la subjetividad sociocultural, la profundidad de las creencias, los sentimientos y las emociones en su análisis de los acontecimientos históricos, que no son más, en esta perspectiva, percibidos simplemente como productos del juego «objetivo» de las fuerzas económicas o políticas. Aun distinguiendo cuidadosamente los milenarismos primitivos de los revolucionarios modernos, no deja de mostrar su afinidad electiva. Esto no quiere decir que todos los movimientos revolucionarios sean milenaristas en sentido estricto o, peor todavía, que respondan a un quiliasmo de tipo primitivo. Eso no impide afirmar que la afinidad entre los dos sea un hecho fundamental en la historia de las revueltas campesinas contra la modernización capitalista. Se trata de una de las hipótesis de investigación más interesantes esquematizadas en sus trabajos de esta época. Hobsbawm ilustra sus propósitos con dos estudios de caso apasionantes: el anarquismo rural en Andalucía y las ligas campesinas de Sicilia, ambos surgidos a fines del siglo xIX con prolongaciones al siglo xx.
\end{abstract}

Palabras clave: Milenarismo; Quiliasmo; Camponeses; Revoluções; Capitalismo.

\section{Eric Hobsbawm, sociologist of peasant millenarianism}

\begin{abstract}
Thanks to the problematic of millenarianism, Eric Hobsbawm's historiography incorporates all the richness of socio-cultural subjectivity - the depth of beliefs, feelings and emotions - into his analysis of historical events, which, from this viewpoint, are no longer perceived simply as products of the «objective» interplay of economic or political forces. Although he makes a careful distinction between primitive millenarianisms and modern revolutionary movements, Hobsbawm nevertheless shows their elective affinity between them. This does not mean that all revolutionary movements are millenarian in the strict sense or - which is even worse - that they are connected to a primitive type of chiliasm. All the same, the affinity between them is a basic fact in the history of peasant revolts against capitalist modernization. This is one of the most interesting research hypotheses outlined by Hobsbawm in his work of that period. He illustrated his idea in two fascinating case studies: rural anarchism in Andalusia and the Sicilian peasant leagues, both arising at the end of the nineteenth century and continuing into the twentieth.
\end{abstract}

KeYwords: Millenarism; Chiliasm; Peasantry; Revolutions; Capitalism.

\footnotetext{
Lowy, Michael. Eric Hobsbawm, sociólogo do milenarismo campesino. Estudos Avançados [online]. 2010, vol.24, n.69, pp. 105-118. ISSN $0103-4014$. São Paulo. Puesto en línea 21 de noviembre del 2012. http://dx.doi.org/10.1590/S0103-40142010000200007. Traducción del portugués al español por el magíster César Espinoza Claudio, Universidad Nacional Mayor de San Marcos, EAP de Sociología, Lima, Perú.
} 
C omo historiador interesado en ciencias sociales, Eric Hobsbawm presentó, gracias a sus trabajos sobre el milenarismo campesino, un abordaje muy significativo en lo tocante a la sociología de las religiones. Se trata de una de las dimensiones de su investigación pionera sobre las formas dichas de revueltas "primitivas». Judío de cultura alemana, nacido en Egipto, en 1917, educado en Viena y Berlín, y más tarde en Oxford y Cambridge, Hobsbawm es uno de los mayores historiadores ingleses del siglo xx. Intelectual de izquierda, representa, ante todo, a un hombre del Iluminismo: ¿no define él al socialismo como el último heredero del racionalismo del siglo xviII? Por lo tanto, no es de extrañar que la distinción entre «moderno» y "primitivo» o "arcaico» ocupe un lugar importante en sus trabajos. ${ }^{1}$

En este sentido si examinamos algunos de sus escritos, y, en particular, las dos obras de los ańos 1959-1969 dedicadas a las formas arcaicas de las revueltas, percibimos que el abordaje se distingue de modo evidente de la vulgata "progresista» gracias a su interés, simpatía, fascinación asimismo - los términos son de él一 por los movimientos "primitivos» de resistencia y protesta antimoderno (anticapitalista) de los campesinos. Es sobre todo el caso de Primitive rebels (1959) y Bandits (1972). ${ }^{2}$ Son también escritos que se aproximan mucho de cierta problemática de las ciencias sociales. En la introducción al primero, Jacques Le Goff comentaba: gracias a su «sentido de las semejanzas estructurales, su sensibilidad histórica desemboca en horizontes sociológicos y antropológicos». De hecho, esta obra es el resultado de una serie de conferencias del autor en la Universidad de Manchester, seguidas de debates con amigos sociólogos y antropólogos marxistas como, Peter Worsley - especialista en los mesianismos primitivos en la Melanésia (el "Cargo Cult») — y el africanista Max Gluckman (Hobsbawm, 1966, p.10, 13).

Esta actitud de apertura a lo "primitivo" - a la vez metodológica, ética y política- implica un

1 Si colocamos sistemáticamente aspas en las palabras "primitivo" o «arcaico» - lo que no siempre ocurre con Hobsbawm- es para indicar cierta distancia crítica en relación a términos que son útiles pero, aun así, bastante marcados por una visión evolucionista o «modernista» de la historia.

2 No nos ocuparemos aquí de los trabajos de Eric Hobsbawm sobre el campesinado, publicados a lo largo de los años 1970 e incluidos en la notable Antología Uncommon People (Hobsbawm, 1998). Su problemática es diferente, y no se refieren (o lo hacen poco) al aspecto que me interesa en el presente texto, el milenarismo. distanciamiento en relación a cierta historiografía, que tiende —en virtud de aquello que él denuncia como un prejuicio racionalista y «modernista»- a desatender tales movimientos, considerándolos como supervivencias bizarras o fenómenos marginales. Ahora, insiste Hobsbawm, estas poblaciones "primitivas", sobre todo rurales, son aún hoy —o sea, los años 1950 - la gran mayoría de las naciones, en la mayor parte de los países del mundo. Además de esto, y ahí está el argumento decisivo para el historiador, «el despertar de su conciencia política hizo de nuestro siglo el más revolucionario de la historia» (Hobsbawm, 1966, p.15-6; 1959, p.2-3). En otras palabras, este tipo de movimiento, lejos de ser marginal, es la fuente o la raíz de las grandes perturbaciones revolucionarias del siglo $\mathrm{xx}$, en la que campesinos y las masas pobres de los campos tuvieron un papel decisivo: la revolución mexicana de 1911-1919, la rusa de 1917, la española de 1936, la china y la cubana. La idea, solo sugerida por Hobsbawm, que no se ocupa directamente de ninguno de esos acontecimientos, constituye una especie de segundo plano en sus investigaciones sobre los "primitivos». ${ }^{3}$

Para comprender estas revueltas, observa Hobsbawm, es preciso partir de la constatación de que la modernización, la irrupción del capitalismo en las sociedades campesinas tradicionales, la introducción del liberalismo económico y de las relaciones sociales modernas significan para ellas una verdadera catástrofe, un auténtico cataclismo social que las desarticula completamente (out of joint es el término inglés intraducible). Quiere este advenimiento del mundo capitalista moderno ser un proceso insidioso, por la operatividad de las fuerzas económicas que los campesinos no comprenden; es una irrupción brutal, por la conquista o cambio de régimen, que ellos lo ven como una agresión mortal a su modo de vida. Las revueltas campesinas de masas contra este nuevo orden son vividas como insoportablemente injustas, y que están frecuentemente inspiradas por la nostalgia del mundo tradicional, del «viejo y buen tiempo» —más o menos mítico- y que asumen la forma de una especie

3 Desafortunadamente, tal pista no es seguida por Hobsbawm en su Historia del siglo xx: él muestra de modo bastante pertinente como el proceso de la modernización conduce, después de la Segunda Guerra Mundial, a una espectacular declinación del campesinado, pero no propone la cuestión de las resistencias campesinas a esta declinación y no examina de manera más sistemática el papel de los estratos campesinos "primitivos» en los grandes movimientos revolucionarios del siglo (cf. Hobsbawm, 1994, p.289-94). 
de «ludismo político» (Hobsbawm, 1966, p.16, 83, 137; 1959, p.3, 67, 119).

Esto se aplica, por ejemplo, a la forma arcaica de revuelta que es el bandidismo social, que Hobsbawm define, curiosamente, como «reformista», porque apunta a "corregir errores", sin tocar en las estructuras sociales existentes. El bandido seńorial puede también, en ciertos casos, hacerse un «revolucionario tradicionalista», apuntando a restablecer la «buena vieja» Iglesia o al «buen viejo» rey. Finalmente, puede volverse milenarista, soñando con un «mundo totalmente nuevo que no conocerá el mal», un mundo de igualdad, fraternidad y libertad, en una «espera del Apocalipsis». Este tipo de sueńo milenarista es inherente a la sociedad campesina. De hecho, el bandidismo social y el milenarismo - que son las formas de reforma y de revolución más primitivas- «caminan juntas históricamente». De hecho, frecuentemente los bandidos señoriales reconocen, "consciente o inconscientemente, la superioridad del sueño milenarista o revolucionario en relación a sus propias actividades». Esta es la razón por la cual Lampião, el legendario bandido del Nordeste brasileño de los años 1920 era sumiso, con su banda de cangaceiros, al líder mesiánico de la ciudad de Juazeiro, el padre Cícero (Hobsbawm, 1972, p. 19-21). Este ejemplo no es muy feliz, en la medida en que el padre Cicero no tenía nada de revolucionario y era milenarista en menor medida; más interesante fue el caso de los Canudos, un villarejo formado por los huidos de la ley y campesinos pobres, adeptos del profeta milenarista Antonio Consejero, que a finales del siglo XIX (1869-1897) van a luchar, como leones, contra el Ejército de la República brasileña, una invención del Diablo. Es cierto que las doctrinas del Consejero dicen mucho más respecto a lo que Hobsbawm llama «tradicionalismo revolucionario», y que no era un movimiento socialmente subversivo del campesinado pobre y de los «bandidos sociales». ${ }^{4}$

En efecto, de todas las formas de revuelta "primitiva», los movimientos milenaristas parecen ser, a los ojos del historiador, los más aptos a volverse revolucionarios. Existiría entre el milenarismo y la revolución una especie de "afinidad afectiva» — se trata de nuestra terminología y no la de Hobsbawm (Löwy,

4 Hobsbawm menciona Canudos en una nota a pie del capítulo sobre el milenarismo lazzarettista de Les primitifs de la révolte (Hobsbawm, 1966, p.89): «La rebelde Siáo de Canudos combatió verdaderamente hasta el último hombre». El acontecimiento fue objeto de una de las mayores obras de la literatura brasileña, Los sertóes, de Euclides de la Cunha.
1988)—, una analogía estructural: La esencia del milenarismo, la espera de un cambio completo y radical del mundo que se reflejará en el milenio, un mundo liberado de todos sus defectos, no es un monopolio del primitivismo. Este está presente, casi por definición, en todos los movimientos revolucionarios sin excepción, y los elementos «milenaristas" pueden ser descubiertos en todos, en la medida en que son inspirados por ideales.

Los movimientos milenaristas arcaicos en Europa han, añadido a este, tres trazos característicos: 1. El aspecto revolucionario, o sea, el rechazo profundo y total del cruel mundo que existe y la apasionada de otro mejor; 2. una ideología del tipo "quiliasta», generalmente de inspiración mesiánico judaicocristiana; 3. una indefinición fundamental en cuanto a los medios de realizarse la nueva sociedad (Hobsbawm, 1966, p. 73). 5 Las investigaciones de Hobsbawm se concentran en tres tipos de milenarismos campesinos: los que parecen ser, antes de todo, religiosos, los que son a la vez religiosos y sociopolíticos, y los que parecen ser puramente seculares. A pesar de estas diferencias, no por eso dejan de pertenecer a un tipo de matriz sociocultural común. ${ }^{6}$

Todos los ejemplos estudiados aquí conciernen a la Europa del Sur - Italia y España. Curiosamente, Eric Hobsbawm, contrariamente a sus compañeros y amigos como Christopher Hill y E. P. Thompson, no se interesó en estudiar los movimientos milenaristas en Inglaterra. Es cierto que redactó, con George Rudé, un estudio brillante sobre un movimiento campesino inglés, una revuelta "primitiva» contra la modernización capitalista, bajo la forma de «ludismo» («movimiento de destrucción de las máquinas»). Sin embargo, tal movimiento de 1830, dirigido por un legendario «capitán Swing», no tiene trazos milenaristas; de cualquier modo, los autores no hacen referencia a esto en su estudio. En otro trabajo, dedicado a la cuestión del papel del metodismo en la agitación revolucionaria en Inglaterra, a finales del siglo xviII, Hobsbawm llega a la conclusión de que los metodistas llamados "primitivos» y otras corrientes disidentes tal vez hayan favorecido A la agitación radical en algunos sectores medios populares (mineros, textiles), sin, todavía, haber ejercido un papel determinante. En buena

\footnotetext{
5 Según Hobsbawm, las otras religiones, en la medida en que consideran el mundo como estable o cíclico, favorecen en menor medida el desarrollo del milenarismo. La hipótesis es discutible.

6 Somos nosotros los que proponemos esta tipología; esta no se halla
} formulada de ese modo en Hobsbawm. 
cuenta, estamos lejos del milenarismo campesino español o italiano (Hobsbawm \& Rude, 1969).

El milenarismo revolucionario se remonta, según Hobsbawm, a Joaquim de Fiore (1135-1202), ${ }^{7}$ el inventor de la doctrina de las Tres Edades del Mundo: la Edad del Padre (la Ley), la del Hijo (la Fe) y el futuro, del Espíritu Santo. Este profeta milenarista — calificado por Norman Cohn como el inventor de la dialéctica profética más pujante que la Europa conoció antes de la aparición del marxismo- plantea una distinción entre el régimen de la justicia en derecho, que esencialmente significa la reglamentación equitativa de las relaciones sociales en una sociedad imperfecta, y el reino de la libertad, que es la sociedad perfecta: Reforma y Revolución... (Hobsbawm, 1966, p. 25). Conforme vamos a ver, algunos de los movimientos milenaristas del siglo xIx, que él va a estudiar, son herederos lejanos del joaquimismo.

Leyéndo los trabajos de Eric Hobsbawm, es evidente que el milenarismo ejerció sobre él una verdadera fascinación -lo que no impidió, evidentemente, la distancia crítica-. Se trata, escribe él, de un fenómeno que "será siempre intensamente emocionante para todos aquellos a quién la suerte de los hombres no deja indiferentes» (ibidem, p. 124). Gracias a la problemática del milenarismo, la historiografía de Hobsbawm integra toda la riqueza de la subjetividad sociocultural, la profundidad de las creencias, los sentimientos y las emociones en su análisis de los acontecimientos históricos, que no son más, en esta perspectiva, percibidos simplemente como productos del juego "objetivo" de las fuerzas económicas o políticas. Esta apertura a la dimensión subjetiva (religiosa) se traduce también por el hecho de que el análisis en términos de clases sociales no elimina el lugar irreductible de los individuos — tanto célebres como desconocidos - a los cuales el historiador frecuentemente concede la palabra.

7 ¿De dónde viene el interés de Eric Hobsbawm por el milenarismo, en sus escritos de finales de los años 1950? En una conversación con nosotros, en 20 de marzo de 1982, él sugería tres explicaciones posibles: «Es tal vez a causa de mi participación en un movimiento revolucionario. Era, de hecho, la época del XX Congreso del PCUS y se sentía la necesidad de un balance general, de cuestionamiento. Finalmente, fui influenciado por antropólogos que trabajaron este tema, sobre todo Max Glucksmann y sus discípulos, como Peter Worsley, que, en la época, era mi compañero de partido». Curiosamente, Eric Hobsbawm no parece interesarse por las fuentes judaicas, proféticas y mesiánicas, veterano-testamentarias del milenarismo. Contrariamente a otros intelectuales judíos de cultura alemana - Ernst Bloch o Walter Benjamin—, no da la impresión de estar motivado por sus orígenes judaicos en lo que concierne al interés por los movimientos milenaristas.
Aunque establezca cuidadosamente la distinción entre milenarismos primitivos y revolucionarismos modernos, no deja de insistir sobre su parentesco (o afinidad) electiva: «Asimismo los revolucionarios modernos menos milenaristas traen en sí una noción de 'imposibilismo' que los hace primos de los taboritas y de los anabaptistas, parentesco que jamás negaron» (ibidem, p.80).7 Tal fórmula remite probablemente a los escritos de Ernst Bloch, que Hobsbawm conocía bien, sobre todo a Thomas Münzer, théologien de la révolution (1921), en la que el anabaptismo es presentado como el ancestro de los movimientos revolucionarios modernos.

Esto no quiere decir que «todos» los movimientos revolucionarios sean milenaristas en el sentido estricto o digan algo respecto a un quiliasmo de tipo primitivo. $\mathrm{E}$, inversamente, cualquier movimiento milenarista no es necesariamente revolucionario. ${ }^{8}$ Por tanto, la distinción no se hace fácilmente. Tomemos el caso, estudiado por Hobsbawm en Los rebeldes primitivos, la agitación mesiánica en torno al profeta — de inspiración joaquimista- David Lazzaretti, en Toscana, alrededor de 1870. Según varios investigadores italianos, por ejemplo M. Barzelotti, se trataría de un movimiento puramente religioso, sin implicaciones políticas. Eric Hobsbawm (1966, p.81) contesta vigorosamente a tal hipótesis y propone otro abordaje, cuya significación metodológica en lo tocante a la sociología de las religiones ultrapasa ampliamente el caso en discusión: el tipo de comunidad que produjo las herejías milenaristas no se presta a una distinción muy clara entre lo religioso y lo secular. Discutir acerca de saber si una secta es religiosa o social no tiene fundamento, pues ella será siempre y automáticamente, de un modo o de otro, las dos cosas.

Esta hipótesis -el laberinto, el mestizaje, el hibridismo, la osmosis entre lo religioso y lo sociopolítico- es una de las contribuciones más interesantes de sus investigaciones sobre el milenarismo campesino.

En el ejemplo toscano, además de esto, tal mezcla es difícilmente contestable: el profeta y sus discípulos, los lazaretistas estaban apasionadamente interesados por la política: su bandera tenía la insignia «La República es el Reino de Dios», una divisa bastante subversiva

8 Hobsbawm, en este paso, se disocia del trabajo de Norman Cohn — The Pursuit (persecución) of the Millenium (1957)—, acusándolo, no sin razón, de borrar — con una intención política evidente - cualquier diferencia entre los dos. 
en la Italia monarquista de la época. Cuando andaban en procesión, cantaban: Nosotros seguimos la Fe/ Para salvar la madre patria / Viva la República / Dios y la libertad.

David Lazzaretti predicaba a favor de la «República de Cristo", lo que, a los ojos de las autoridades del reino, era absolutamente inaceptable (ibidem, p.81-2).

Eric Hobsbawm comienza con un análisis sociológico, económico e histórico de la base social lazzarettista: se trata de poblaciones pobres, sobre todo campesinas, de la región de Monte Amianta, una de las más atrasadas, económica y culturalmente (analfabetismo macizo) de Toscana. Con la unificación del país, las leyes del Piemonte fueron impuestas como las generales de Italia, bajo la forma de un código económico liberal impiedoso que tuvo consecuencias sociales desastrosas en regiones como esa. Por ejemplo, la ley forestal que suprimió los derechos costumbristas a los pastajes comunes y a la cosecha de la leña para el calentamiento. Además de esto, nuevos impuestos decretados por el Parlamento provocaran el alza del precio de la comida, generando motines de hambre y revueltas en toda Italia: en 1867 hubo 257 muertos, 1.099 heridos y 3.788 prisioneros en el país (ibídem, p. 84).

David Lazzaretti nació en 1834. Era un carrocero que se convirtió en 1868 y comenzó a presentarse como un nuevo profeta, un nuevo pastor del Sinai, un reformador, un legislador listo a liberar al pueblo que gemía, «sometido por el despotismo a la esclavitud». Tenía por tarea reconciliar la Iglesia con el pueblo para formar una milicia de jóvenes italianos, «la milicia del Espíritu Santo" y realizar la regeneración del orden moral y civil. Al principio gozó de cierta protección de la Iglesia Católica, hostil a la monarquía, al gobierno impío, y a las ideas liberales seculares. Por tanto, su propagación, inspirada en las herejías populares y doctrinas joaquimitas - tres reinos sucesivos, la Gracia, la Justicia y el Espíritu Santo, inminente, tercera y última edad del mundo- y, en 1878, cuando él se presenta como el Mesías es inmediatamente denunciado por la Iglesia y será excomulgado por el Vaticano. Esto no lo amilanó —al contrario-su influencia creció sobre los campesinos del Monte Amianta, que abandonaban las iglesias para unirse al nuevo profeta. En efecto, en 18 de agosto, descendió de la montańa a la ciudad de Arcidosso, seguido por tres mil de sus partidarios, cantando himnos y cargando la bandera de la República de Dios y los otros traían el uniforme de la "Milicia del Espíritu Santo", aunque sin las armas. Frente a los guardias que los intimaron a dispersarse, David Lazzaretti respondió: «Si desean la paz, yo les traigo la paz... si quieren sangre, aquí me tienen». Los guardias dispararon al azar y Lazzaretti fue uno de los muertos; sus apóstoles supervivientes fueron juzgados y condenados. A lo largo del siglo xx, los que se consideraban aún sus discípulos se aproximaron al movimiento comunista, que lo respetaba como su precursor. En 1948, cuando se intentó el asesinato de Palmiro Togliatti, un levantamiento popular espontáneo ocurrió en Arcidosso, según el comentario de Hobsbawm, fue «una segunda edición, revista y corrección, del descenso del Monte Amianta» (ibídem, p. 82-6). ${ }^{9}$

El lazzarettismo revela, a su manera, que la afinidad entre milenarismo y revuelta es un dato fundamental en la historia de las resistencias campesinas contra la modernización capitalista. Se trata, me parece, de una de las hipótesis de investigación más interesantes esbozadas por Hobsbawm en sus trabajos de esa época. Él va a ilustrar su propósito con otros dos estudios de casos enteramente apasionantes: uno, a la vez religioso y social, las ligas campesinas de Sicilia, y el otro, en principio antirreligioso, el anarquismo rural en Andalucía: ambos originarios del siglo XIX, con prolongaciones en el xx.

El anarquismo agrario de Andalucía se desarrolló a lo largo de revueltas periódicas, durante los ańos de 1870-1917, produciéndose un último evento en 1931, con la proclamación de la República en España. Curiosamente, Hobsbawm no se interesó por el estudio del anarquismo rural en la Catalunya y en Aragón, que conoció un desarrollo espectacular en los ańos de 1936-1937, al comienzo de la guerra civil espańola. Probablemente porqxue el advenimiento del anarco-sindicalismo moderno en España, a lo largo del siglo $\mathrm{xx}$, representa, en su opinión, por la organización metódica, la disciplina, la estrategia y la táctica, un paso más frente a la "espontaneidad pura y del mesianismo" que caracterizaba los levantamientos "primitivos» de las primeras décadas del movimiento libertario (ibídem, p. 107). Esta distinción es legítima, mas, a nuestra manera de ver, las colectivizaciones agrarias del «breve verano de la anarquía» de 1936-1937, incitadas

$9 \quad$ El autor de estas líneas (Michel Löwy) pudo participar, en 2003, de una especie de peregrinación de intelectuales de izquierda, italianos y extranjeros, a la tumba de David Lazzaretti. 
por Durriti y sus amigos, tenían mucho en común con las rebeliones andaluzas «milenaristas» del pasado.

Según Hobsbawm, las revueltas tienen, sin duda, causas económicas, pero no pueden ser descritas como «motines del hambre»: "cuando los hombres realmente tienen hambre, quedan muy ocupados en buscar comida para poder hacer otra cosa». La mejor explicación para tal revolucionarismo social endémico es «la introducción de las relaciones jurídicas y sociales capitalistas en los campos meridionales durante la primera mitad del siglo XIX». La imposición del libre mercado de las tierras y la concentración de las propiedades latifundistas cambiaron la distribución de las fuerzas operantes: así alrededor del ańo de 1931, el $80 \%$ de la población rural no poseían tierra alguna, mientras que seis mil grandes propietarios detentaban el $56 \%$ de las rentas tributarias. A esto es preciso añadir la evolución del catolicismo español desde finales del siglo XVIII, cada vez más asociado a las clases dominantes y alejadas de los campesinos (ibidem, p.96-7). Por tanto, en el último cuarto del siglo XIX, los propagandistas anarquistas llegaron a un espacio favorable, difundiendo las ideas de Bakunin y Kropotkin. Obtuvieron tal éxito porque «ningún movimiento político de los tiempos modernos había reflejado de modo tan sensible y tan preciso, las aspiraciones espontáneas de los campesinos primitivos». Para estudiar el comunismo libertario andaluz, el historiador inglés se apoyó en los trabajos de un jurista de inicio del siglo, F. Diaz del Moral, autor de una voluminosa Histoire des agitations agraires dans la Province de Cordoue (Madrid, 1929) y en una investigación personal en el villarejo de Casas Viejas (Cadiz), uno de los epicentros de la revuelta campesina.

Por cierto, este movimiento no tiene nada de religioso, en el sentido habitual del término; al contrario, se oponía violentamente a la Iglesia Católica, no necesitando poner fuego en las iglesias y conventos. Según Hobsbawm, tal actitud «reflejó probablemente la amargura de los campesinos frente a la traición de los pobres' por la Iglesia». Ferozmente antirreligioso, no por esto deja de ser «el ejemplo más claro del movimiento de masa moderno milenarista o casi milenarista». Por su revolucionarismo simple, el rechazo total y absoluto del mundo perverso y opresivo, la fe absoluta en el «Día del Gran Cambio», y en la llegada de un mundo de Justicia y Libertad, este movimiento comunista libertario - que correspondía de manera perturbadora a los sentimientos de los campesinos andaluces y a su rechazo del nuevo orden capitalista- se constituía en algo "utópico, milenarista, apocalíptico» (ibídem, p. 99-106).

Tanto Diaz del Moral, observador contemporáneo, como el propio Hobsbawm emplean una terminología «religiosa» para describir tal fenómeno: el movimiento fue inspirado por "apóstoles bakuninistas» que trajeron «la buena palabra», las brochuras (slogans) de Kropotkin y Malatesta discutidos con «fervor y gravedad» por los campesinos andaluces. El «nuevo evangelio» se esparció espontáneamente de un villarejo a otro: los "convertidos» se entregaron a un «ardiente proselitismo" y atrajeron para su ideal a amigos y compañeros de trabajo. Estos nuevos «apóstoles» se beneficiaron frecuentemente del apoyo de todo el villarejo, sobre todo "cuando la frugalidad de su existencia venía a testificar su fe». Alrededor de 1900, las noticias del debate internacional sobre la nueva huelga general alcanzaron el espacio de Andalucía, y los campesinos realizaron, en numerosos villarejos, «huelgas mesiánicas», o sea, paralizaciones del trabajo espontáneas y macizas, sin la más pequeña reivindicación, sin que nadie intentara negociar: se entraba en huelga "por cosas más importantes que los salarios». El objetivo verdadero era la revolución social, y si las personas luchaban era "para acelerar la llegada del milenio». Esta última era concebido como un cambio «de tal modo total y apocalíptica» que nada quedaría del antiguo mundo de opresión y desigualdad: sería el comienzo de un mundo justo «en el cual los que habían sido los últimos serían los primeros y los bienes de esta tierra serían divididos entre todos». En la visión de ellos, «la pujanza del milenio era tal que, si de hecho viniera, ni aún la aristocracia podría resistirla» (ibídem, p. 103-6).

¿Qué significa este vocabulario «religioso»? ¿Se trata de una simple metáfora, un raciocinio por analogía? ¿Se trató de analizar el anarquismo campesino andaluz como un milenarismo secularizado? ¿O de sugerir una matriz milenarista común a fenómenos religiosos y seculares? Por tanto ¿qué es preciso entender por «milenarismo»? Hobsbawm no responde a estas cuestiones, pero, en un pasaje de su libro, intenta determinar la especificidad milenarista del movimiento libertario: las sublevaciones agrarias anarquistas «son evidentemente revolucionarias, su única finalidad era la realización de la subversión fundamental. Eran milenaristas en el sentido que lo entendemos, en la medida en que ellos mismos no debían hacer la revolución»; esta «acabaría por realizarse ya que 
habían manifestado tal esperanza» (ibídem, p. 105). El argumento no nos parece convincente, pues, si estos campesinos se rebelaban y algunas veces instauraban un (efímero) comunismo libertario en su villarejo - como muestra Hobsbawm acerca de la revuelta de Casas Viejas en 1933-, es porque realmente deben «ellos mismos» hacerlo, sin esperar que aquello «acabe por realizarse». Hobsbawm parece reconocerlo, escribiendo, algunas líneas después: «lo que parecía ser una demostración milenarista podía ser solo lo menos ineficaz de las técnicas revolucionarias disponibles» (ibídem, p. 105-6). En suma, lo que diría respecto al milenarismo - bajo una forma secular - sería sobre todo la estructura de la visión revolucionaria, la ruptura total e inmediata con el pasado y la venida del reino de la justicia integral. En buena cuenta, podemos preguntarnos si los comunistas libertarios andaluces no representan, de una forma particularmente radical, lo que Hobsbawm define como la dimensión milenarista inevitable de cualquier movimiento revolucionario.

El otro movimiento milenarista revolucionario estudiado por Hobsbawm son las ligas campesinas de Sicilia. Se trata de un ejemplo opuesto al movimiento lazzarettista. Aparentemente secular, presenta las reivindicaciones que nada tenían de milenaristas, como la abolición de las tasas y de los derechos de importación de mercancías, una reforma de los arrendamientos agrícolas etc. Sin embargo, expresa también una aspiración revolucionaria que no podía, en el seno de estos campesinos sicilianos, dejar de tomar una forma milenarista y «religiosa»: por lo tanto, no es de extrañar que las grandiosas y emocionantes esperanzas revolucionarias depositadas por los campesinos en los Fasci [ligas campesinas] se hayan expresado en los términos milenaristas tradicionales». Como en Andalucía, que presenta semejanzas marcantes con Sicilia, los campesinos se rebelaron, a finales del siglo XIX, contra la introducción de las relaciones capitalistas en el campo — cuyas consecuencias fueron agravadas por la depresión agraria mundial de los años de 1880-. Este movimiento tomó forma con la fundación y expansión de las ligas campesinas, generalmente con dirección socialista, seguidas de revueltas y huelgas, en una escala que asustó al gobierno italiano, llevándolo, en 1894, a utilizar tropas para apagar el peligro. ¿Por qué los propagadores anarquistas —entre los cuales se encontraban brillantes intelectuales como Enrico Malatesta- que intentaron cubrir el sur de Italia no tuvieron el mismo éxito de Espańa — a pesar de las semejanzas evidentes entre los campesinos de las dos regiones - y fueron ultrapasados por los agitadores socialistas (marxistas)? Las tentativas del historiador inglés para explicar esta diferencia no dieron resultado, y él constató que solo un conocimiento profundo de la historia y de la sociología de Espańa y del Reino de las dos Sicilias permitiría comprenderla (ibídem, p. $114-6) .^{10}$

El movimiento es "primitivo" y milenarista en la medida en que el socialismo predicado por las ligas era, a los ojos de los campesinos sicilianos, una nueva religión, la verdadera religión de Cristo - traicionada por los padres aliados a los ricos - que anunciaba la venida de un mundo nuevo, sin pobreza, fe y frío, conforme a la voluntad de Dios. Cruces e imágenes santas son cargadas en sus manifestaciones, y el movimiento, que contaba con una importante participación femenina, se extendió, entre 1891-1894, como una epidemia: las masas campesinas estaban excitadas por la creencia mesiánica de que la irrupción de un nuevo reino de justicia era inminente. En una atmósfera de exaltación, los grupos de convertidos se encargaban de esparcir la feliz noticia, "pues en un periodo milenarista, como vimos en Andalucía, cada uno se transforma en propagandista». Al mismo tiempo, como muestran innumerables testimonios, "no es de dudar que la esperanza de los campesinos fuera la revolución, una sociedad nueva, justa, igualitaria y comunista». Es el caso, por ejemplo, de las impresionantes declaraciones de una campesina del villarejo de Piana di Greci (reproducidas entre los documentos adjunto al libro): «Nosotros deberíamos ser todos iguales [...] Bastaría poner todo en común y dividir equitativamente lo que es producido", en una sociedad en que "reine un espíritu fraterno» (ibídem, p. 114-6, 121, 123). Resta saber si el milenarismo es una estructura mental, un substrato cultural permanente, o solamente una irrupción momentánea, un "periodo» de corta duración: Eric Hobsbawm parece sugerir las dos cosas a la vez, o sea, una "mentalidad» milenarista que se manifiesta, de forma radical, en ciertos momentos de crisis y de revuelta.

Ciertamente, observa Hobsbawm, que las ligas campesinas no son milenaristas en el sentido lazzarettista o anarquista andaluz. Sin embargo, en el contexto campesino siciliano —estas «personas

10 Estas organizaciones campesinas también son llamadas «Fasci», pero, para evitar confusiones disgustables, prefiero utilizar el término «ligas» que aparece igualmente en el texto de Hobsbawm. 
primitivas vueltas fanáticas por una nueva fe», según el liberal A. Rossi-, la enseńanza socialista, por el simple hecho de ser revolucionario, "debía tener aspectos fuertemente milenaristas». Contrariamente a lo acontecido en Andalucía, la nueva religión no acarreaba una ruptura abierta en relación a la antigua, cristiana: para la campesina de Piana di Greci, Jesús era un verdadero socialista y deseaba precisamente lo que las ligas campesinas exigían. Dicho de otro modo: el movimiento no era religioso, sino «las aspiraciones de los campesinos se expresaban automáticamente en una terminología religiosa» (ibídem, p. 117-8).

El movimiento de las ligas campesinas sicilianas presenta, en la visión de Hobsbawm, un carácter ejemplar, en la medida en que se trata de una organización agraria milenarista y "primitiva» que se vuelve "moderna» por la adhesión al socialismo y al comunismo. A pesar de la derrota en 1894, los movimientos campesinos permanentes pudieron, gracias a las prácticas organizacionales modernas de los socialistas, constituirse en ciertas regiones de Sicilia y fueron heredados por el movimiento comunista, después de la gran Guerra. La historia del villarejo de Piana di Greci ilustra esta continuidad: epicentro de las revueltas, a finales del siglo XIX, es, aún en los ańos 50 del siglo $\mathrm{xx}$, un bastión comunista: «su viejo entusiasmo milenarista tomó una forma más duradera: la submisión permanente y organizada a un movimiento social-revolucionario moderno». Tal evolución, según Hobsbawm, no es un simple cambio de lo «arcaico» a lo "moderno", sino una especie de «integración dialéctica» —en el sentido de la Aufhebung hegeliano-marxista- del primero en el segundo: la experiencia de Piana «muestra que el milenarismo no es obligatoriamente un fenómeno temporal, pero puede, en condiciones favorables, ser el fundamento de una forma de movimiento permanente y extremadamente resistente» (ibídem, p. 121-2).

En otros términos: el milenarismo no debe ser considerado únicamente como "una supervivencia tocante de un pasado arcaico», sino una fuerza cultural que permanece activa, bajo otra forma, en movimientos sociales y políticos modernos. La conclusión que propone, al final de su capítulo dedicado a las ligas campesinas sicilianas tiene, evidentemente, un alcance histórico social y político más largo y universal:

Cuando está «ligado» a un movimiento moderno, el milenarismo puede no solamente volverse políticamente eficaz, sino que puede venir a serlo sin perder aquel celo, aquel fervor, la inquebrantable confianza en un mundo mejor y esa generosidad emotiva que lo caracteriza aún en sus formas más primitivas y pervertidas. (ibídem, p. 123-4)

Tal observación puede ser considerada un poco como la «moral de la historia» del conjunto de sus escritos sobre el milenarismo y las revueltas primitivas.

Los trabajos de Eric Hobsbawm levantan cuestiones que interesan acerca de la sociología de las religiones: ¿cuáles son las condiciones sociales (y económicas) que favorecen el desarrollo de los movimientos milenaristas? ¿Cuáles son sus relaciones con la cultura «arcaica» - precapitalista - de las capas campesinas? ¿Cuáles pueden ser las relaciones entre lo religioso, lo social y lo político en el milenarismo campesino? ¿Existe una matriz común en los movimientos religiosos y sociopolíticos de tipo milenarista? Él no siempre ofrece respuestas a estas interrogantes, pero su abordaje es extremadamente fecundo. Sería interesante comparar sus investigaciones con las de otros científicos sociales atraídos por los mesianismos y milenarismos, como Karl Mannheim, Ernst Bloch o Henri Desroches.

Nos parece que Eric Hobsbawm inauguró, en este caso, un apasionante campo de investigación que merece ser conocido no solamente por los historiadores, sino también por los sociólogos o antropólogos políticos, estudiosos de los fenómenos actuales. Citaremos solamente dos ejemplos de nuestro propio campo de investigación como sociólogos interesados en América Latina: el Ejército Zapatista de Liberación Nacional (EZLN) de Chiapas (México) y el Movimiento de los Campesinos Sin Tierra (MST) de Brasil. Ambos son movimientos campesinos de protesta (y resistencia) contra la modernización capitalista, teniendo en común los componentes milenaristas que los aproximan de los fenómenos estudiados por el historiador inglés, fundamentalmente modernos por su programa, reivindicaciones, prácticas y formas de organización. El propio Eric Hobsbawm escribió varios artículos bastante interesantes sobre los movimientos campesinos en América Latina, sobre todo en el Perú y en Colombia, a lo largo de la segunda mitad del siglo xx, mas él no los analiza bajo el ángulo del milenarismo.

El EZLN nació de la fusión, en las montañas de Chiapas, del guevarismo de un puñado de militantes urbanos (que no deja de tener una dimensión 
milenarista) como una revuelta "arcaica» de las comunidades indígenas mayas y con el mesianismo cristiano de las comunidades de base (fundadas los ańos 1970 por el obispo de Chiapas, monseñor Samuel Ruiz), bajo la égida suprema de la leyenda milenarista de Emiliano Zapata. El resultado de este coctel político-cultural, social y religioso explosivo fue una de las rebeliones campesinas más originales de los años 1990.

La sublevación zapatista de enero de 1994 ciertamente estaba dirigida contra la opresión secular de los indígenas mayas por las autoridades y por los propietarios latifundistas, pero era directamente motivada por las medidas de modernización neoliberal del gobierno federal: la privatización de las comunidades rurales («ejidos») consagradas por la revolución mexicana y el acuerdo de libre comercio con los Estados Unidos (ALENA) que amenazaba arruinar la cultura tradicional de maíz de las comunidades indígenas - base, hace milenios, de su identidad cultural -, abriendo México al maíz transgénico de las empresas norteamericanas del agro negocio.

El movimiento zapatista se distinguió también por un componente libertario, que se manifiesta tanto en la autogestión de los villarejos cuánto por su rechazo en apostar al juego político e inclusive autorizar la «toma del poder». Esta es la razón por la cual los movimientos anarquistas o anarcosindicalistas, que experimentan cierta renovación de actividad, sobre todo en Europa del sur, hicieron de la solidaridad con los insurgentes de Chiapas uno de sus principales ejes de intervención.

En cuanto al MST brasileńo, que tiene sus raíces socioculturales en la Pastoral de la Tierra de la Iglesia, en las comunidades de base y en la teología de la liberación, ella se caracteriza también por una mezcla asombrosa de religiosidad popular, revuelta campesina «arcaica» y organización moderna, en una lucha radical por la reforma agraria y, por el futuro, de una «sociedad sin clases». Con un fuerte componente emocional, «místico»-es el término que utilizan los propios militantes para designar el estado de espíritu de los participantes - o «milenarista» (en el sentido amplio), la semejanza con las ligas campesinas sicilianas de 1890 es marcante. Este reúne centenares de miles de campesinos, parcelarios y trabajadores agrícolas, y se volvió actualmente en el más importante movimiento social de Brasil y la principal fuerza de protesta contra la política de modernización neoliberal de los sucesivos gobiernos brasileños.

A juzgar por estos ejemplos del siglo XXI, el milenarismo revolucionario — la forma más radical de las resistencias campesinas contra la modernización capitalista-, tal como fue estudiado por Eric Hobsbawm, no es necesariamente un fenómeno del pasado.

\section{Referencias bibliográficas}

Hobsbawm, E. (1957). Methodism and the Threat of Revolution in Britain. History Today, v.I. VII.

Hobsваwм (1959). Primitive Rebels. Studies in Archaic Forms of Social Movement in the 19th and 20th centuries. New York: Norton Library.

Новьвашм (1966). Les primitifs de la révolte dans l'Europe moderne. Paris: Fayard.

Новьвашм (1970). Rebeldes primitivos: estudos sobre formas arcaicas de movimentos sociais nos séculos XIX $e X X$. Rio de Janeiro: Zahar.

Hoвsвawm (1972). Bandits. París: Maspero.

Новзвашм (1976). Bandidos. Río de Janeiro: Forense Universitária.

Hoвsваwм (1994). Age of Extremes. The short twentieth century 1914-1991. London: Penguin.

Hoвsваwm (1998). Uncommon People. New York: The New Press.

Новзвашм (2008). Era dos extremos: o breve século XX, 1914-1991. São Paulo: Cia. das Letras.

Hobsbawm, E.; Rude, G. (1969). Captain Swing. London: Lawrence and Wishart.

Новsваwm, E.; Rude, G. (1982). Capitão Swing: a expansão capitalista e as revoltas rurais na Inglaterra no início do século XIX. Río de Janeiro: Francisco Alves.

Lowy, M. (1988). Rédemption et utopie. Le judaïsme libertaire en Europe Centrale. Une étude d'affinité élective. París: PUF. 